\title{
Disease-Suppressive Vermicompost Induces a Shift in Germination Mode of Pythium aphanidermatum Zoosporangia
}

\author{
Eric A. Carr and Eric B. Nelson, Department of Plant Pathology \& Plant-Microbe Biology, Cornell University, Ithaca, NY 14853
}

\begin{abstract}
Carr, E. A., and Nelson, E. B. 2014. Disease-suppressive vermicompost induces a shift in germination mode of Pythium aphanidermatum zoosporangia. Plant Dis. 98:361-367.

Compost amendments to soils can minimize losses from soilborne plant pathogens, yet the mechanisms by which this occurs have not been well elucidated. In the present study, developmental responses of Pythium aphanidermatum zoosporangia to vermicomposts were observed to better understand how suppression of Pythium seedling disease is expressed. Mature zoosporangia were exposed to vermicompost extracts (VCEs) and monitored using time-lapse photomicroscopy. Sterile and nonsterile VCEs inhibited indirect germination and viable zoospore production whereas zoosporangia germinated directly in VCE to produce germ tubes. Additional treatments were tested to determine factors that promote direct over indirect germination. The $\mathrm{pH}$ (5 to 9 at

$0.001 \mathrm{M})$ and ionic strength $(0.1$ to 0.0001 at $\mathrm{pH}$ 6) of potassium phosphate buffer did not alter zoosporogenesis compared with sterile water. Decreasing osmotic potentials in glucose and sucrose from -248 to $-2,712 \mathrm{kPa}$ or in polyethylene glycol 8000 from -0.335 to $-105 \mathrm{kPa}$ led to a decrease in indirect germination with a corresponding increase in direct germination. Significant levels of seed infection were observed within $1 \mathrm{~h}$ of exposure to zoospores (produced in sterile water) or to germ tubes (produced in sucrose solution). Our data demonstrate that VCEs suppress zoosporogenesis and stimulate direct germination; however, this did not result in the suppression of germ tube growth and seed infection.
\end{abstract}

Composts and other organic amendments are increasingly being used in agriculture to minimize losses from plant diseases (17). However, disease suppression with composts has been quite variable (42), limiting the widespread adoption of compost applications to control plant diseases in diverse cropping systems. Developing a better understanding of how composts suppress pathogens and diseases could increase the predictability of compost-induced disease suppression and, thereby, improve their effectiveness. Despite numerous investigations of compost-induced disease suppression, our understanding of the mechanisms that may lead to disease suppression remain insufficient to predict the pathosystems, soil conditions, and environmental conditions for which disease suppression may occur (17).

Previous approaches to identify factors involved in disease suppression have focused largely on comparative analyses of the bulk properties of suppressive and nonsuppressive composts (7). A consistent pattern that has emerged from these studies is the central role of microbial activity in compost-induced disease suppression (17). For Pythium seedling diseases in particular, the subset of bacteria that colonize seed shortly after sowing may be the most critical for disease suppression $(8,9)$ because of their direct interference with pathogenesis in the infection court (10). The significance of such a spatial and temporal synchrony between plant-associated microbial activities and developmental responses of pathogens during infection emphasizes the importance of understanding these direct interactions to further identify the mechanisms that underlie disease suppression.

Pythium aphanidermatum causes seed and seedling rots in over 60 different genera of plant hosts (15). Zoospores of $P$. apha-

Corresponding author: E. B. Nelson, E-mail: ebn1@ cornell.edu

* The $\boldsymbol{e}$-Xtra logo stands for "electronic extra" and indicates that five supplementary videos are available in the online edition.

Accepted for publication 24 September 2013.

http://dx.doi.org/10.1094/PDIS-05-13-0466-RE

(C) 2014 The American Phytopathological Society nidermatum and many other zoosporic pathogens are often considered the main developmental stage responsible for plant infection (29) and, therefore, the most likely stage affected by pathogensuppressive microbes. During zoosporogenesis, zoosporangia germinate through an indirect germination mode by first giving rise to spherical vesicles into which zoosporangial cytoplasm is transported and where zoospores are subsequently differentiated and released (18). Once released, it is believed that zoospores are attracted to various sugars and amino acids present in seed and root exudates or electrical fields surrounding roots where they swim chemotactically toward the host surface $(28,29,43)$. After reaching the host surface, zoospores attach, encyst, germinate, and then penetrate host tissues (29).

Although many studies aimed at understanding the suppression of zoosporic oomycete pathogens have focused on the suppression of zoospore chemotaxis $(13,22)$ and arrival at the host surface (36), it is likely that any disruption of zoosporangial development, including vesicle development, zoospore release, chemotaxis, attachment, encystment, or germination, could equally result in disease suppression. Although the factors that influence host-pathogen interactions after zoospores are released have been described (12), little is known about factors that may influence zoosporogenesis upstream of zoospore release. Pythium zoosporogenesis is known to be influenced by changes in abiotic conditions such as the transfer of cultures from nutrient-rich to nutrient-poor media or to water, or from changes in water relations and fluxes of cations $(38,39,44)$. However, microbial mechanisms of zoosporogenesis suppression remain unknown.

The goal of this study was to examine the developmental responses of $P$. aphanidermatum zoosporangia when exposed to a disease-suppressive compost to better understand how suppression of Pythium seedling disease occurs. It is currently unknown if zoosporangial development prior to zoospore release is susceptible to suppression but we predict that inhibition of any stage during zoosporogenesis (cytoplasmic cleaving and emptying, vesicle formation, zoospore differentiation, or zoospore release) would decrease the potential for zoospore inoculum to infect plants, ultimately leading to a reduction in disease incidence. In addition, we attempt to identify additional biological and biophysical factors that influence zoosporogenesis and address how they relate to compost-induced disease suppression. 


\section{Materials and Methods}

Maintenance and production of $P$. aphanidermatum zoosporangia. To maintain pathogen virulence and prevent bacterial contamination, surface-disinfested nontreated cucumber seed $(\mathrm{Cu}$ cumis sativus 'Marketmore 76') were inoculated with $P$. aphanidermatum zoospores by placing nine seeds in a dish containing mature zoosporangia grown for 3 to 4 days on green bean agar (GBA; described below). Sterile water $(10 \mathrm{ml})$ was added to the zoosporangial culture, which was then incubated at $27^{\circ} \mathrm{C}$ for 24 h. Seed that were visibly infected (discolored or rotted radicle) were transferred to sterile plastic petri dishes. A solidified medium (referred to as KWARP medium), which consisted of $2 \%$ agar with kanamycin sulfate at $0.025 \mathrm{mg} / \mathrm{ml}$, rifampicin at $0.015 \mu \mathrm{g} / \mathrm{ml}$, and penicillin at $0.015 \mu \mathrm{g} / \mathrm{ml}$ was placed on top of the seed and incubated at $27^{\circ} \mathrm{C}$ for 2 to 3 days; then, hyphal tips were transferred to GBA. To prevent carryover of antibiotics from KWARP to GBA, an additional subculture step was carried out (4-mm-diameter culture plugs from GBA to fresh GBA plates) and incubated at $27^{\circ} \mathrm{C}$ for 3 days before use in experiments.

P. aphanidermatum (Edson) Fitzp. (Pa58) (5) was cultured on GBA, a medium modified from Nelson and Craft (30), prepared first by boiling $20 \mathrm{~g}$ of $1.0-\mathrm{cm}$-long frozen cut green beans in 1 liter of water for $20 \mathrm{~min}$. This boiled mixture was then filtered through four layers of cheesecloth. Agar (10 g; Difco) was then added to $500 \mathrm{ml}$ of filtrate along with the following ingredients, each separately dissolved in $100 \mathrm{ml}$ of sterile water: $5 \mathrm{ml}$ of 0.1780 $\mathrm{M} \mathrm{K}_{2} \mathrm{HPO}_{4}, 5 \mathrm{ml}$ of $0.1176 \mathrm{M} \mathrm{KH}_{2} \mathrm{PO}_{4}, 50 \mu \mathrm{l}$ of $0.0501 \mathrm{M}$ thiamine $\mathrm{HCl}, 5 \mathrm{ml}$ of $0.4011 \mathrm{M}\left(\mathrm{NH}_{4}\right)_{2} \mathrm{SO}_{4}, 5 \mathrm{ml}$ of $0.10 \mathrm{M} \mathrm{CaCl}_{2}, 5$ $\mathrm{ml}$ of $0.20 \mathrm{M} \mathrm{MgSO}_{4} \cdot 7 \mathrm{H}_{2} \mathrm{O}, 0.5 \mathrm{ml}$ of $0.0999 \mathrm{M}$ asparagine, and $5 \mathrm{ml}$ of $0.0999 \mathrm{M}$ D-glucose. The final $\mathrm{pH}$ of GBA was 6.87. The GBA was then autoclaved for $30 \mathrm{~min}$. Before cooling, $3 \mathrm{ml}$ of sterile GBA was aliquoted to sterile 5-cm-diameter glass petri dishes. This resulted in a thin layer of medium suitable for subsequent microscopic examination. Using a 4-mm-diameter corer borer, four culture plugs were evenly transferred to GBA, approximately $5 \mathrm{~mm}$ from the edge of the dish, and incubated at $27^{\circ} \mathrm{C}$ for 3 days at which time zoosporangia had formed for use in subsequent experiments.

Compost preparation and use in experiments. A vermicompost suppressive to $P$. aphanidermatum zoospore infections of cucumber (A. L. H. Jack and E. B. Nelson, unpublished) was used for our studies. Solid vermicompost was prepared at RT Solutions, Inc. using a dairy manure feedstock. Dewatered dairy manure solids were mixed with spoiled corn and hay silage plus cured thermophilic dairy manure compost at a ratio of $7: 1: 1$, respectively. The mixture was composted thermogenically in a forced-air system for up to 2 weeks. This material was then fed every 3 to 4 days in 5 -cm layers to a continuous flow-through vermicomposting system stocked with the earthworms Eisenia fetida and Dendrobaena venata. Finished vermicompost was removed 75 days after the initiation of thermophilic composting from the underside of the continuous flow-through system and sieved to $10-\mathrm{mm}$ particle size. Vermicompost was stored at $-20^{\circ} \mathrm{C}$, then thawed at room temperature for $24 \mathrm{~h}$ in the dark prior to use in experiments. The percent dry weight of the vermicompost was $42 \%$.

Our studies necessitated the use of liquid vermicompost extracts (VCEs) instead of the solid material because of the need to visualize rather rapid developmental changes during zoosporogenesis that could not be monitored easily in the solid material. Therefore, a series of nonsterile VCEs were prepared consisting of 1.7, 2.7, 5.3, 27.6, or $30.5 \mathrm{~g}$ in $100 \mathrm{ml}$ of sterile Nanopure water. The solid vermicompost was measured, added to a plastic container, and then $100 \mathrm{ml}$ of sterile Nanopure was added to the container. The surface-to-volume ratio of the container was 0.686. Mixtures were gently mixed, then incubated at $27^{\circ} \mathrm{C}$ for $4 \mathrm{~h}$. The supernatant was then filtered twice through Whatman number 1 filter paper to remove fine particulates. The final $\mathrm{pH}$ of nonsterile VCE $(30.5 \%$ [wt/vol]) was 8.4.

Sterilized VCEs $(30.5 \%$ [wt/vol]) were also prepared in two ways. First, heat-sterilized VCE was prepared by autoclaving the solid vermicompost three times prior to producing extracts as described above. Second, filter-sterilized VCE was prepared by filtering the nonsterile extract through a $0.2-\mu \mathrm{m}$ filter. All liquid extracts were prepared fresh for each zoosporangial germination assay.

Zoosporangial germination assays. Zoosporangial germination was monitored using time-lapse photomicroscopy. The influence of $\mathrm{pH}$ on zoosporangial germination was evaluated by preparing a range of potassium phosphate buffers to create aqueous solutions at $\mathrm{pH} 5,6,7,8$, and 9. To evaluate the impact of ionic strength on zoosporangial germination, a series of 10 -fold dilutions were prepared in sterile water from the $0.1 \mathrm{M} \mathrm{KPO}_{4}$ solution $(\mathrm{pH}$ 6) to obtain ionic concentrations of $0.1,0.01,0.001$, and $0.0001 \mathrm{M}$. All liquid solutions were autoclaved for $30 \mathrm{~min}$.

The influence of osmotic potential on zoosporangial germination was evaluated using solutions of polyethylene glycol 8000 (PEG), sucrose, and glucose. PEG was prepared in $100 \mathrm{ml}$ of sterile water to obtain osmotic potentials of $-0.335(0.08 \mathrm{~g}),-4.0(0.8 \mathrm{~g})$, and $-105.0 \mathrm{kPa}(8.0 \mathrm{~g})$. Glucose and sucrose solutions were prepared in water to obtain osmotic potentials of $-247.6(0.1 \mathrm{M}),-1,238(0.5$ $\mathrm{M})$, and $-2,467(1 \mathrm{M}) \mathrm{kPa}$ for glucose and $-271.2(0.1 \mathrm{M}),-1,356$ $(0.5 \mathrm{M})$, and $-2,712(1.0 \mathrm{M}) \mathrm{kPa}$ for sucrose. The osmotic potentials for PEG were calculated using the following equation: $\Psi=$ $1.29[\mathrm{PEG}]^{2} \mathrm{~T}-140[\mathrm{PEG}]^{2}-4.0[\mathrm{PEG}]$, where $\Psi=$ osmotic potential (bars), $[\mathrm{PEG}]=$ grams of $\mathrm{PEG}$ per gram of $\mathrm{H}_{2} \mathrm{O}$, and $\mathrm{T}=$ temperature $\left({ }^{\circ} \mathrm{C}\right)(27)$. The osmotic potentials for glucose and sucrose were calculated using the following equation: $\Psi=-\mathrm{CiRT}$, where $\Psi$ = osmotic potential $(\mathrm{mPa}), \mathrm{C}=$ solute concentration $(\mathrm{mol} / \mathrm{liter}), \mathrm{i}=$ solute ionization constant, $\mathrm{R}=$ gas constant, and $\mathrm{T}=$ temperature (K) (31). All osmotic potentials were converted to $\mathrm{kPa}$. Sterile water was used as a control for inducing indirect germination, viable vesicle formation, and subsequent zoospore release. All liquid solutions were autoclaved for $30 \mathrm{~min}$.

To examine the impacts of these aqueous treatments as well as the impacts of sterile and nonsterile VCE treatments on zoosporangial germination, $10 \mathrm{ml}$ of solution (described above) was applied to a glass petri dish containing zoosporangia formed after 3 days on GBA and incubated at $25^{\circ} \mathrm{C}$ for 4 to $7 \mathrm{~h}$. Subsequent germination was captured using a $\times 10$ water-immersion lens on a Zeiss compound microscope outfitted with an Olympus digital DP71 camera, and images were processed using Olympus DP2-BSW software. The observation location, which was selected typically from the margins of a culture plate, was chosen to maximize the quantity of zoosporangia ( $>20$ zoosporangia) within a $1.0-\mathrm{mm}^{2}$ viewing area. A single time-lapse video was recorded each time a treatment was applied to zoosporangia (hereafter referred to as a flooding event). Based on preliminary observations, greater than $95 \%$ of zoosporangia germinated indirectly in sterile water $4 \mathrm{~h}$ after flooding; therefore, a 4-h time-lapse duration was set for osmotic potential treatments and all VCE treatments. To observe any prolonged effects on zoosporangial germination, a 7-h time lapse was used for ionic strength and $\mathrm{pH}$ experiments. The interval for image capture was $10 \mathrm{~s}$ for indirect germination and vesicle formation in sterile water and 5 min for all other germination observations.

At the end of each flooding event, zoosporangia were scored either as (i) viable and indirectly germinating (vesicles formed with subsequent germ tube production or swimming zoospores), (ii) nonviable and indirectly germinating (vesicles or zoospores lysed or no activity observed from vesicles), (iii) directly germinating (germ tubes present), or (iv) nongerminated (no zoosporangial germination or other activity observed). For most analyses, both viable and nonviable indirectly germinating zoosporangia were combined in one category designated as indirect germination. The percentage of zoosporangia displaying each germination mode was calculated for each flooding event. For example, the percent direct germination $=$ (number of zoosporangia germinating directly/total number of observable surface zoosporangia on GBA) $\times 100$. The mean for each percent germination mode per treatment across replicates was determined. At least three biological replicates (= three replicate flooding events) were used for each treatment, ex- 
cept for the ionic concentration experiment, where only two replicates were used. The growth rate of germ tubes from directly germinating zoosporangia was determined using time-lapse photomicroscopy. Ten replicate zoosporangia from each of three flooding events were selected for germ tube growth rate measurements, which were taken during the first $30 \mathrm{~min}$ of germ tube growth.

Bioassay design. Nontreated cucumber seed (C. sativus Marketmore 76) were used in all bioassays. Seed were sorted to remove damaged seed, individually screened to a weight range of 0.02 to $0.03 \mathrm{~g} / \mathrm{seed}$, surface disinfested with $0.5 \%$ sodium hypochlorite for $2.5 \mathrm{~min}$, rinsed with sterile water, and air dried prior to use in experiments. Quartz sand was initially dry-sieved to a 0.5 - to 1.0-mm-diameter particle size range, wet-sieved to remove fine particulates, and then autoclaved for $30 \mathrm{~min}$ three times before use. Zoosporangia were grown on GBA for 3 days as described above and the surface zoosporangia were quantified and ranked for abundance on a scale of 0 to 5 , with each increasing rank category corresponding to an approximately $10 \times$ increase in the number of surface zoosporangia. Such quantification facilitated the selection of three replicate culture plates with relatively equal numbers of zoosporangia per plate. Six cucumber seed were added to each culture plate containing zoosporangia. Zoosporangia were forced to germinate indirectly in $3 \mathrm{ml}$ of sterile water to produce swimming zoospore inoculum, and directly in $3 \mathrm{ml}$ of either sterile sucrose solution $(0.5 \mathrm{M},-1,356 \mathrm{kPa})$ or $30.5 \%$ (wt/vol) VCE to produce germ tube inoculum. For making comparisons between inoculum types as they relate to disease suppression, $30.5 \%$ (wt/vol) VCE was used in bioassays because it was the only VCE treatment to completely inhibit viable indirect germination and zoospore production. Noninoculated treatments served as controls. Flooded plates were incubated at $27^{\circ} \mathrm{C}$ for $1,2,3$, and $4 \mathrm{~h}$. Three replicate plates were used per incubation time per treatment.

At hourly intervals, $3 \mathrm{ml}$ of sterile sand was placed in each well of a 12-well plate, an individual seed was transferred from the incubating petri dishes to each well, an additional $3 \mathrm{ml}$ of sand was added over the seed, and then each well received $1.25 \mathrm{ml}$ of sterile water. The culture plate lids were sealed with Parafilm, placed in clear plastic bins (23.5 by 10.5 by $31.0 \mathrm{~cm}$, width by height by length, respectively; five plates per bin), and then incubated at $27^{\circ} \mathrm{C}$ for 3 days with $14 \mathrm{~h}$ of light. Tissue culture plate lids were removed after 3 days and $250 \mathrm{ml}$ of distilled water was added to the bottom of the plastic bins to create a moisture chamber. The bin lids were then reattached and sealed with Parafilm. Bins were then incubated at $27^{\circ} \mathrm{C}$ for an additional 4 days. After incubation, seed or seedling survival was recorded as a binary variable to account for varied disease symptoms and strengthen statistical analyses. The following seed or seedling conditions received a value of 0: (i) nongerminated seed, (ii) radicle present but shoot absent, (iii) seed or seedling completely rotten, or (iv) seedling still standing but with symptoms on both the cotyledons and the shoot. The following seedling conditions received a value of 1: (i) symptoms present only on the cotyledons, (ii) symptoms present only on the shoot, or (iii) no observable symptoms. All bioassay experiments were repeated three times.

Statistical analysis. Differences between the different modes of zoosporangial germination within a treatment and differences in germ tube growth rates were determined using analysis of variance for which means were separated using the Tukey-Kramer HSD test (JMP Pro 9.0). The dominant mode of germination (indirect, direct, or nongerminated) for each flooding event was calculated from the original percent germination data. For example, if the dominant mode of germination during a single flooding event was indirect, then the total number of zoosporangia germinating indirectly was greater than the sum of germination modes direct and nongerminated. The Fisher's exact test, $\chi^{2}$ analysis (JMP Pro 9.0) was used to determine whether a treatment significantly altered the dominant mode of germination compared with sterile water. A binary logistical regression model, least squares means (SAS) was used to determine significant differences in bioassay survival data.

\section{Results}

Zoosporogenesis in the absence of VCE. Maximum zoosporangial production was obtained after 3 days of incubation on GBA at $27^{\circ} \mathrm{C}$ (data not shown). However, despite attempts to normalize the numbers of zoosporangia per plate, the total numbers of zoosporangia varied significantly from plate to plate. For example, from 208 culture plates, the quantity of zoosporangia was 2 to 99 per plate, with a mean of 41 zoosporangia/plate. Despite this variation, zoosporangial germination in sterile water $\left(25^{\circ} \mathrm{C}\right)$ was dominated by indirect germination $(P<0.0001)$ and differed significantly from all other modes of germination $(P<0.05)$ (Fig. 1). Indirect germination in sterile water was characterized by the formation of vesicles in which zoospores differentiated and were subsequently released (Fig. 2A-C). Only low levels of directly germinating or nongerminated zoosporangia were observed. Vesicle formation occurred $78.0 \mathrm{~min}( \pm 6.8$ standard error $[\mathrm{SE}])$ after flooding with sterile water. This was followed by zoospore release $20.8 \mathrm{~min}( \pm 0.4 \mathrm{SE})$ later. During this period, zoosporangial cytoplasm was translocated into the vesicle and then immediately differentiated into between 5 and 20 motile zoospores, depending on the initial size of the zoosporangium (Supplementary Video S1). Within seconds after differentiation, the vesicle membrane burst and swimming zoospores were released. At this time, vesicles were no longer visible and zoosporangial walls were only faintly visible (Supplementary Video S2). Vesicle production continued intermittently but at a relative constant rate up to $7 \mathrm{~h}$, by which time nearly all zoosporangia had germinated indirectly (Fig. 3).

Zoosporangial germination in the presence of VCE. Nonsterile VCEs significantly $(P<0.0001)$ altered the mode of zoosporangial germination compared with that observed in sterile water (Supplementary Video S3). At low VCE concentrations (1.7 to $5.3 \%[\mathrm{wt} / \mathrm{vol}])$, germination was unchanged and nearly all zoosporangia germinated indirectly by forming vesicles and zoospores. However, at a concentration of $27.6 \%$ (wt/vol), VCEs induced an average of $39 \%( \pm 14.6 \mathrm{SE})$ indirect germination (3\% viable indirect and $36 \%$ nonviable indirect germination), whereas an average

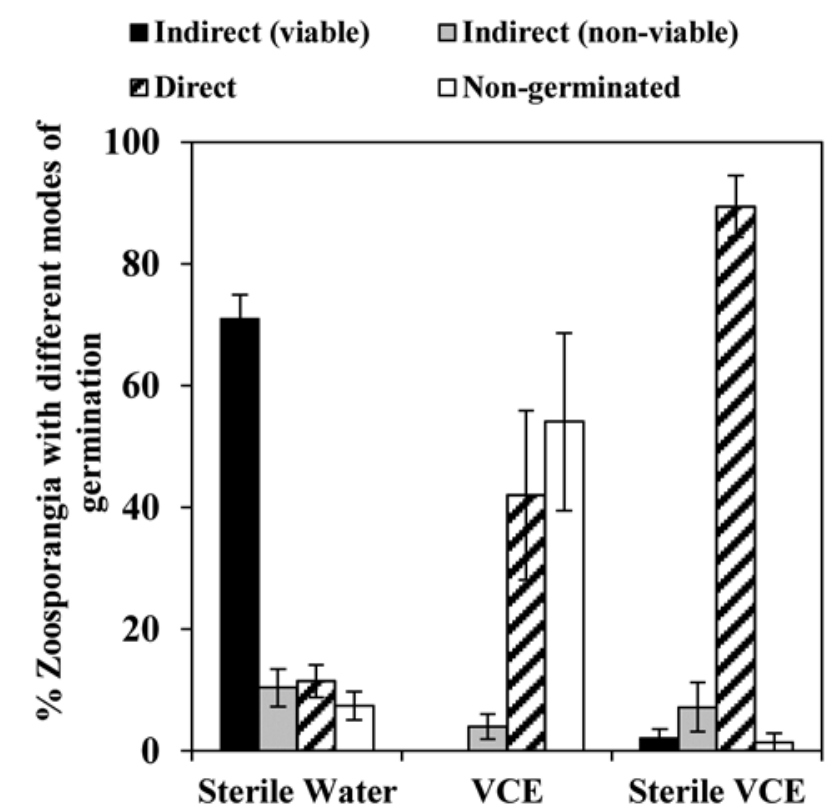

Fig. 1. Effects of vermicompost extracts (VCEs) on Pythium aphanidermatum zoosporangial germination. Ten milliliters of $30.5 \%$ (wt/vol) sterile or nonsterile VCE were applied to zoosporangia and the mode of germination was recorded $4 \mathrm{~h}$ later using time-lapse photomicroscopy. Viable indirectly germinating zoosporangia produced vesicles with subsequent germ tubes or swimming zoospores. Nonviable indirectly germinating zoosporangia produced vesicles or zoospores that lysed in solution. Directly germinating zoosporangia produced germ tubes. Sterile water served as a control; $n=10$ for water, 8 for VCE, and 5 for sterile VCE treatments. Bars represent standard errors. 
of $31 \%( \pm 7.0 \mathrm{SE})$ germinated directly by the formation of a germ tube. The remaining zoosporangia were nongerminated. Direct germination of zoosporangia was characterized by the production of multiple germ tubes (often three per zoosporangium) (Fig. 2DE). At a VCE concentration of $30.5 \%$ (wt/vol), viable indirect germination was completely inhibited while the level of direct germination increased to an average of $42 \%( \pm 13.8 \mathrm{SE})$. The level of nongerminated zoosporangia in $30.5 \%$ (wt/vol) VCE was $54 \%$ ( \pm 14.6 SE) (Fig. 1).

In the presence of heat- or filter-sterilized VCEs $(30.5 \%$ [wt/vol] $)$, germination mode was significantly $(P=0.0003)$ altered compared with that in sterile water (Supplementary Video S4). There was no significant difference $(P>0.05)$ in germination response between heat- and filter-sterilized VCEs (data not shown). As a result, percent germination data from heat- and filter-sterilized VCEs were combined in one category designated as sterile VCE. In the presence of sterilized VCEs, $89 \%( \pm 5.0 \mathrm{SE})$ of the zoosporangia germinated directly by way of germ tubes (Fig. 1). The lysis of vesicles or zoospores (i.e., nonviable indirect germination) was observed in the presence of both sterile and nonsterile VCEs (30.5\% wt/vol) (Fig. 4). Furthermore, in the presence of sterile VCE, the time required for germination $(23.2 \mathrm{~min})$ was significantly reduced relative to that in sterile water (78.0 min). The average germ tube growth rate from all directly-germinating zoosporangia exposed to sterile and nonsterile VCEs was 116.9 $\mu \mathrm{m} / \mathrm{h}( \pm 13.2 \mathrm{SE})$ and did not differ significantly $(P>0.05)$ between sterile and nonsterile VCEs.

Factors influencing zoosporangial germination mode. The percentage of zoosporangia germinating indirectly as well as the time required for germination were unaffected across a $\mathrm{pH}$ range of 5 to $9(P=0.7059)$ or by the molar concentration of a potassium
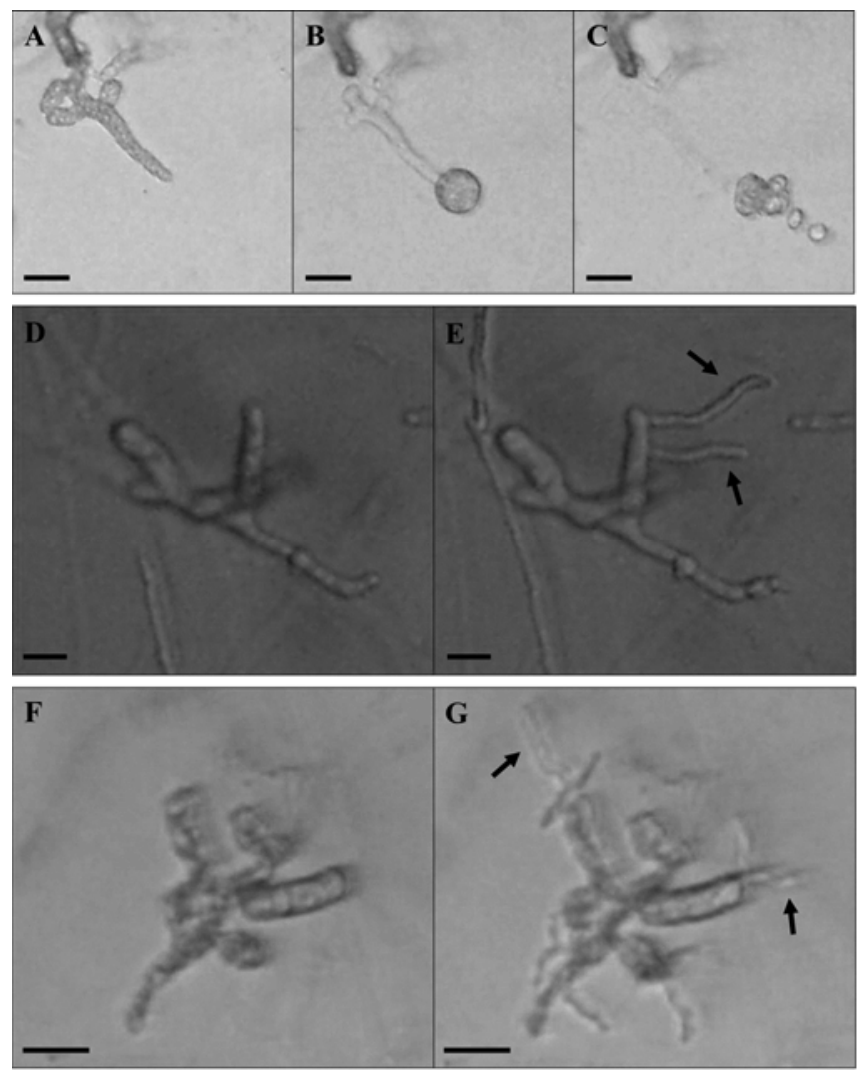

Fig. 2. Germination of Pythium aphanidermatum zoosporangia. A-C, Indirect germination of a zoosporangium flooded with sterile water, scale bars $=25 \mu \mathrm{m}$. A vesicle was produced followed by zoospore release. Elapsed time was approximately $20 \mathrm{~min}$. Direct germination and germ tube production was initiated in treatments of D-E, $30.5 \%$ (wt/vol) nonsterile vermicompost extract, scale bars $=25$ $\mu \mathrm{m}$, and $\mathbf{F}-\mathbf{G}$, sterile $0.5 \mathrm{M}$ sucrose solution, scale bars $=30 \mu \mathrm{m}$. Arrows point to zoosporangial germ tubes. phosphate buffer solution (from 0.001 to $0.1 \mathrm{M}$ ); $P=0.5455$ ) relative to that in sterile water. Although viable indirect germination was nearly inhibited in $0.1 \mathrm{M}$ potassium phosphate buffer $(\mathrm{pH} 6)$, nonviable indirect germination was unaffected and the overall trend in zoosporangial germination was not significantly $(P>0.05)$ different from that in sterile water (data not shown). However, osmotic potentials generated with either sucrose $(P<0.0001)$ (Supplementary Video S5), glucose $(P<0.0001)$, or PEG $(P=0.0046)$ significantly altered germination mode relative to that in sterile water but not the time required for germination to be initiated (Fig. 5). As osmotic potential decreased, the level of viable indirect germination decreased with a corresponding increase in direct germination (Fig. 2F-G); however, indirect germination was observed at all osmotic potentials generated with PEG but not all those generated with sucrose or glucose. The average germ tube growth rate in sucrose solution $(0.5 \mathrm{M},-1,356 \mathrm{kPa})$ and glucose solution $(0.5 \mathrm{M},-1,238 \mathrm{kPa})$ were $119.3 \mu \mathrm{m} / \mathrm{h}( \pm 7.6 \mathrm{SE})$ and 122.3 $( \pm 18.4 \mathrm{SE})$, respectively, and did not differ significantly $(P>0.05)$ from growth rates observed in VCEs. At an osmotic potential of $-2,712 \mathrm{kPa}$ in sucrose $(1.0 \mathrm{M})$, nearly all of the zoosporangia remained nongerminated.

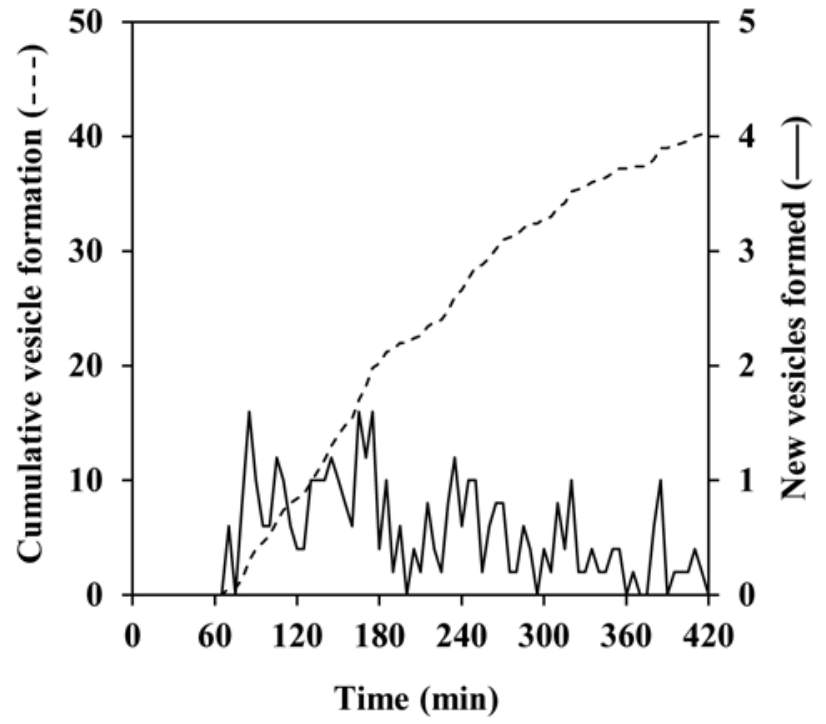

Fig. 3. Mean vesicle formation by Pythium aphanidermatum after flooding with sterile water. Data were averaged from five flooding events with a mean of 36 zoosporangia observed per event.

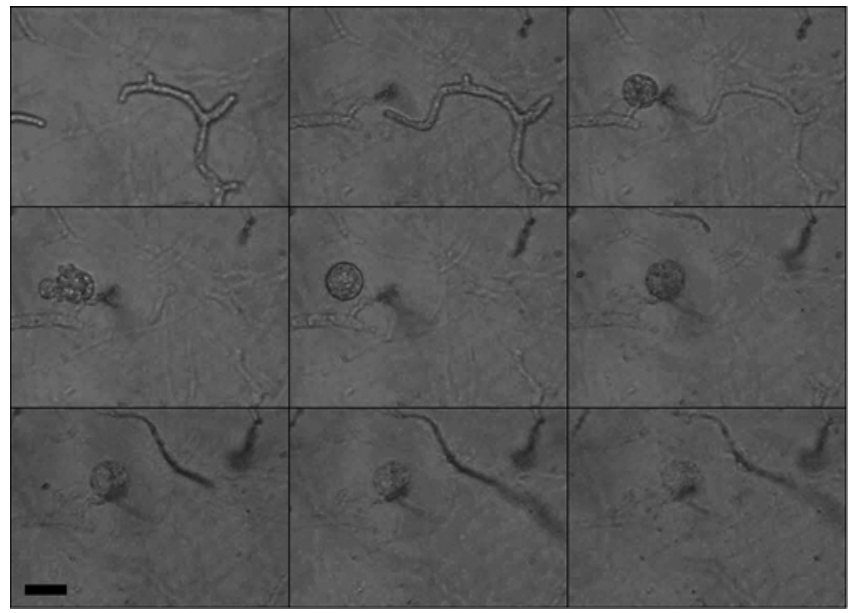

Fig. 4. Nonviable indirectly germinating zoosporangia of Pythium aphanidermatum in nonsterile vermicompost extract $(30.5 \%$ [wt/vol]). The series of images, viewed left to right, top to bottom, represent the temporal progression of zoosporangial germination and vesicular lysis. Approximate elapsed time was $35 \mathrm{~min}$. Scale bar = $25 \mu \mathrm{m}$. 
Bioassay results. Seed and seedling survival decreased significantly $(P<0.0001)$ over a 7-day period when seed were exposed to either zoospores produced in sterile water or germ tubes produced in sucrose solution $(0.5 \mathrm{M},-1,356 \mathrm{kPa}$; Fig. 6A). Significantly greater seedling survival was observed with germ tube inoculum as compared with zoospore inoculum when exposed to seed for 2 and 3 h (Fig. 6A).
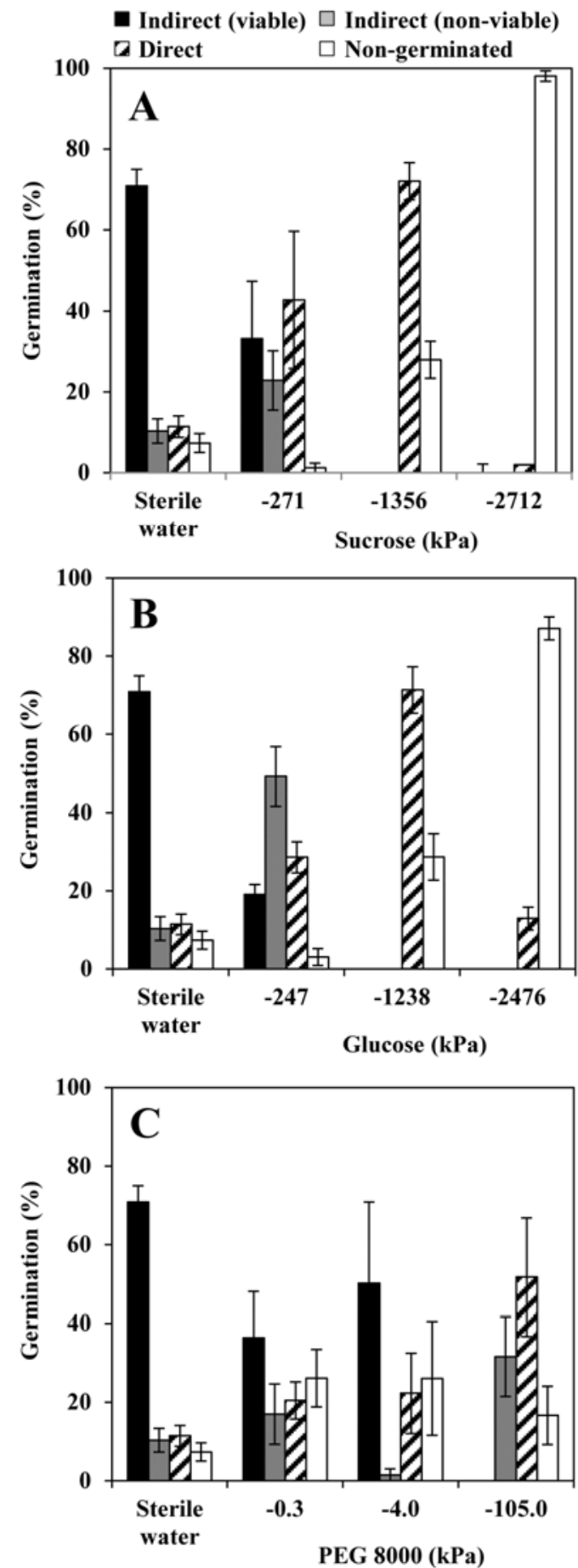

Fig. 5. Pythium aphanidermatum zoosporangial germination at different osmotic potentials. Ten milliliters of A, sucrose solution; B, glucose solution; or C, polyethylene glycol 8000 (PEG) were applied to zoosporangia and the germination mode was recorded $4 \mathrm{~h}$ later using time-lapse photomicroscopy. Viable indirectly germinating zoosporangia produced vesicles with subsequent germ tubes or swimming zoospores. Nonviable indirectly germinating zoosporangia produced vesicles or zoospores that lysed in solution. Directly germinating zoosporangia produced germ tubes. Sterile water served as a control; $n=10$ for water, 5 for sucrose treatments, 3 for glucose treatments, and 3 for PEG treatments. Bars represent standard errors.
Disease was suppressed within $1 \mathrm{~h}$ of germ tube inoculum exposure in treatments of VCE compared with noninoculated controls (Fig. 6B). However, seedling survival decreased significantly in VCE after $2 \mathrm{~h}$ of inoculum exposure and continued to decrease over time. Furthermore, significantly $(P<0.05)$ greater seedling survival was observed in the presence of VCE than in the presence of sucrose solution $(0.5 \mathrm{M},-1,356 \mathrm{kPa})$ when exposed to germ tube inoculum for 1, 2, or $3 \mathrm{~h}$ (Fig. 6B). However, by $4 \mathrm{~h}$ of inoculum exposure, seedling survival did not differ between sucrose and VCE treatments.

\section{Discussion}

Attempts to understand the mechanisms by which oomyceteincited diseases are biologically suppressed have centered largely
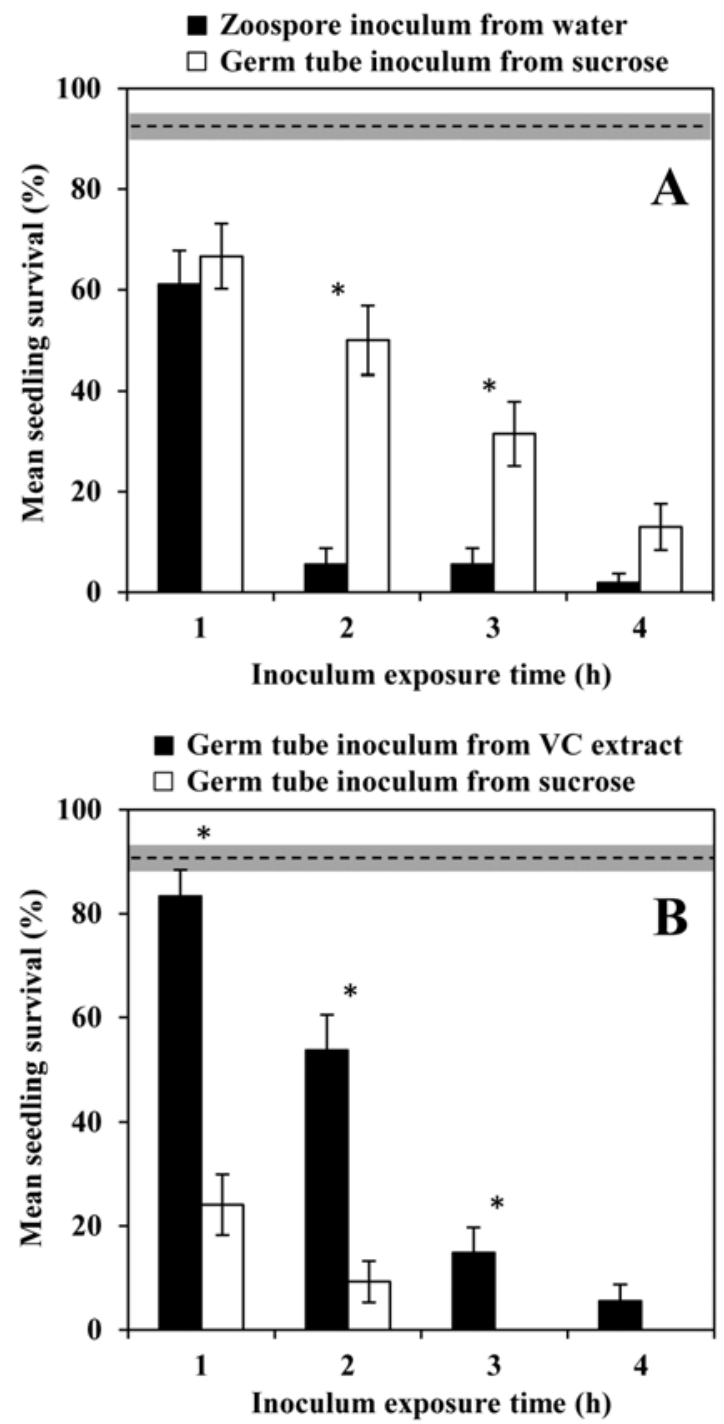

Fig. 6. Effects of Pythium aphanidermatum zoosporangial germination mode on cucumber seedling survival. A, Mean seedling survival after exposure to zoospore and germ tube inoculum $(n=3)$. Zoospore formation was induced in sterile water while germ tubes were induced in sterile $0.5 \mathrm{M}$ sucrose. B, Suppression of germ tube inoculum of $P$. aphanidermatum by vermicompost extracts $(30.5 \%[\mathrm{w} / \mathrm{vol}])$ was compared $(n=3)$. Inoculum produced in sterile $0.5 \mathrm{M}$ sucrose served as a control. For both $A$ and $B$, cucumber seed were incubated with each type of inoculum for 1 , 2,3 , and $4 \mathrm{~h}$ at $27^{\circ} \mathrm{C}$. At each hour, seed were transplanted to sterile sand and grown for 7 days. Noninoculated treatments served as controls. There was not a significant difference between noninoculated treatments $(P<0.05)$. The horizontal dotted line represents the mean survival for seedlings in all noninoculated treatments. The gray horizontal bar represents the standard error $( \pm 1.3)$ of the control treatments. Vertical bars represent standard error; ${ }^{*}$ indicates significant $(P$ $<0.05)$ difference between inoculated treatments within each hour according to binomial logistic regression, least squares means test. 
on observations of zoospore behavior and either the direct lysis of zoospores by biological agents $(16,24,25)$ or the inability of zoospores to reach host surfaces and infect plants $(22,23,36)$. Our work has shown that zoosporangial development prior to zoospore release may be equally vulnerable to interference and suppression, reducing the numbers or infectivity of zoospores arriving at the host surface. Although the timing and sequence of zoosporogenesis stages that we observed in $P$. aphanidermatum in the absence of vermicompost were consistent with observations reported for other Pythium spp. $(20,26,32,44)$, this "normal" course of zoosporogenesis was severely disrupted in the presence of vermicompost, leading to the abortion or lysis of vesicles and complete suppression of zoospore release. Low arrival rates of zoospores on host surfaces and the corresponding low levels of disease due to microbial suppression has been commonly explained by the microbial biosynthesis of zoosporocidal toxins $(1,13,24)$ or antibiotics $(33)$; however, such an interpretation assumes that zoospores are indeed produced during preinfection responses to plants. This is not commonly monitored.

Perhaps the most interesting and puzzling result from our work was the vermicompost-induced change in the mode of zoosporangial germination. Although the indirect germination of zoosporangia was suppressed in VCEs, zoosporangia continued to germinate directly by forming germ tubes. Observing that the mode of germination was shifted in both sterile and nonsterile VCEs suggests that the shift was induced either by nonmicrobial processes or factors or from heat-stable microbial products.

Surprisingly little is known about bimodal germination in $P$. aphanidermatum. Although $P$. aphanidermatum oospores have been observed to germinate biomodally, giving rise to zoosporangia in the absence of glucose but germinating directly to produce germ tubes in the presence of glucose $(34,35)$, this has not been described for $P$. aphanidermatum zoosporangia and, to our knowledge, direct germination of sporangia has only been mentioned once in the literature (40). Stanghellini and Burr (40) observed the formation of germ tubes from $P$. aphanidermatum zoosporangia germinating adjacent to bean and sugarbeet seed and seedlings in soil as well as in the presence of bean seed exudates. Under these conditions, concentrations of glucose and other carbon compounds would be elevated relative to soil in the absence of plants or to water where indirect germination is almost exclusively observed. This raises questions about the relative roles of directly germinating and indirectly germinating zoosporangia in Pythium disease epidemiology.

Much of our understanding of bimodal germination in oomycetes comes from a few very old studies of Phytophthora spp. $(3,4,6,11,41)$, where relatively high temperatures shift the germination mode from indirect to direct. Additionally, plant extracts and exudates, carbohydrates, amino acids, inorganic salts, and low osmotic potentials are also known to induce direct germination $(11,21)$. Studies with $P$. insidiosum have shown that increasing concentrations of various cations reduce the formation and release of zoospores $(38,39)$, although it is not known whether these patterns hold true for $P$. aphanidermatum. However, the previous studies did not determine whether direct zoosporangial germination was alternatively induced while indirect germination was suppressed. Although Shipton (37) observed decreasing zoospore release from $P$. insidiosum zoosporangia with increasing potassium ion concentration up to $0.2 \mathrm{M}$, our results with $P$. aphanidermatum demonstrated that vesicle production (and, hence, germination mode) were unaffected by potassium ion concentrations up to 0.1 $M$, indicating that other factors impact the shift from indirect to direct germination mode.

We were also able to demonstrate that low (increasingly negative) osmotic potentials could induce direct germination of $P$. aphanidermatum zoosporangia. And although the osmotic potentials of the VCEs were unknown, the fact that we observed this in the presence of sterile as well as nonsterile VCEs suggests that factors such as osmotic potentials and not other microbial interactions could potentially explain the shift from indirect germination to direct germination in the presence of VCEs. Water relations are clearly one of the more important factors affecting zoosporogenesis in a wide range of Pythium and Phytophthora spp. (14); therefore, it is not surprising that $P$. aphanidermatum germination mode would be influenced by osmotic potential, especially given that the vermicompost used in our study has a relatively high electrical conductivity (Worm Power, unpublished). Although we did not estimate the osmotic potentials of our VCEs, they are likely to be low given the relatively high levels of dissolved solids (Worm Power, unpublished).

Although our empirical understanding of the factors influencing direct germination in Phytophthora spp. is relatively clear, the significance of direct germination to disease and to disease suppression is currently unknown. Hardy and Sivasithamparam (19) demonstrated that sporangia of Phytophthora drechsleri germinated directly in the presence of microbes that were also shown to suppress disease. However, the capacity of germ tubes to infect plants was not established and the direct suppression of germ tubes by these disease-suppressive microbes was not tested. Our ability to induce direct germination in the absence of vermicompost (i.e., under low osmotic potentials using sucrose) provided a comparative tool for assessing the infectivity and suppression of directly germinating zoosporangia. We would have predicted that VCEs would have suppressed germ tube infections; however, contrary to our prediction, we found that germ tubes were capable of infecting seed placed adjacent to directly germinating zoosporangia. Although greater seedling survival was observed when seed were exposed to directly germinating zoosporangia for 1 to $3 \mathrm{~h}$ in VCE than in the absence of VCE, eventually nearly $100 \%$ seedling mortality was observed, suggesting that any initial levels of disease suppression were masked after an extended exposure to Pythium aphanidermatum germ tubes.

The lack of long-term suppression of germ tubes in VCE observed in our study is somewhat paradoxical, given that the vermicompost used in this study is highly suppressive to $P$. aphanidermatum seed and seedling disease when zoospores are used as inoculum (A. L. H. Jack and E. B. Nelson, unpublished). How can a compost suppress the disease but, at the same time, induce an alternate developmental stage that can still initiate infections? We believe much of this paradox may be due to artifacts of our assay system and we propose three possible explanations to help resolve this paradox. First, our assay system was not conducive for a seedcolonizing bacterial consortium, shown previously to play an important role in compost-induced disease suppression $(8,9)$ and important in suppressing zoospore infections by $P$. aphanidermatum in vermicompost substrates (A. L. H. Jack and E. B. Nelson, unpublished). The seed-associated microbial responses require a minimum of $8 \mathrm{~h}$ to develop (8). In our experimental design, zoosporangia, cucumber seed, and VCEs were incubated simultaneously, which provided little time (approximately $1 \mathrm{~h}$ ) for a suppressive microbial community to colonize the seed surface. Preexposing seed to VCEs may have provided a more accurate experimental setup by allowing a microbial community to develop that was capable of suppressing germ tube infections. Second, the spatial distribution of directly germinating zoosporangia in the spermosphere may play a significant role in disease suppression. For example, $P$. aphanidermatum zoospores are capable of traveling at a speed of 180 to $210 \mu \mathrm{m} / \mathrm{s}$ (2), which is much faster than the growth rate of germ tubes that extend at a mean rate of $117 \mu \mathrm{m} / \mathrm{h}$. The observation that $P$. aphanidermatum zoosporangia germinate indirectly at some distance from a host whereas they germinate directly when adjacent to the host (40) suggests that zoospores of Pythium spp. are the likely infective developmental stage when the distance to the host exceeds the radial extent of the spermosphere and when the influences of compost osmotic potentials are weaker. Seed may avoid germ tube colonization in the presence of vermicompost when the distance between seed and pathogen is relatively large, preventing germ tubes from reaching the seed in advance of a suppressive seed-colonizing community developing. Therefore, it is possible that the suppressive effects of VCEs were obscured in our assay system because cucumber seed were placed 
in such close proximity to germinating zoosporangia. Finally, the overwhelming exposure of germ tube inoculum may have eliminated any spatial factors that could have influenced disease suppression.

In summary, our results have revealed that compost-induced disease suppression may influence multiple stages of pathogen development that may involve both microbial and nonmicrobial factors. A key observation was the clear lysis of vesicles in the presence of VCE, thus preventing zoospore formation but also the accompanying shift in the germination mode from indirect germination by way of zoospores to direct germination by way of germ tubes. This is one of the few reports of direct germination in zoosporangia of $P$. aphanidermatum. Whereas the factors responsible for the vesicle lysis are currently unknown, low osmotic potentials that could have been generated by the VCE may have been responsible for the shift toward direct germination, and this should be investigated in the future. Although we demonstrated that germ tubes can initiate seed infections, the shift away from zoospores to germ tubes could explain disease suppression in vermicompost if the spatial distribution of zoosporangia is considered. Because indirect germination results in a greater number of infective units capable of reaching hosts over a larger spatial area than would occur with germ tubes, lower levels of disease would occur from directly germinating zoosporangia. Our work highlights the importance of understanding developmental aspects of the pathogen life cycle and in particular the stages of the life cycle that lead most proximally to plant infection in better understanding the processes that may lead to disease suppression.

\section{Acknowledgments}

We thank the United States Department of Agriculture Small Business Innovation Research, NYSTAR Center for Advanced Technology, and the Andrew W. Mellon award for funding; Worm Power, Avon, NY for vermicompost; and W. Falcheck for technical assistance.

\section{Literature Cited}

1. Abdalla, M. A., Win, H. Y., Islam, M. T., von Tiedemann, A., Schuffler, A., and Laatsch, H. 2011. Khatmiamycin, a motility inhibitor and zoosporicide against the grapevine downy mildew pathogen Plasmopara viticola from Streptomyces sp. ANK313. J. Antibiot. 64:655-659.

2. Appiah, A. A., van West, P., Osborne, M. C., and Gow, N. A. R. 2005. Potassium homeostasis influences the locomotion and encystment of zoospores of plant pathogenic oomycetes. Fungal Genet. Biol. 42:213-223.

3. Aragaki, M., and Hine, R. B. 1963. Effect of radiation on sporangial production of Phytophthora parasitica on artificial media and detached papaya fruit. Phytopathology 53:854-856.

4. Aragaki, M., Mobley, R. D., and Hine, R. B. 1967. Sporangial germination of Phytophthora from papaya. Mycologia 59:93-102.

5. Ben-Yephet, Y., and Nelson, E. B. 1999. Differential suppression of cucumber damping-off caused by Pythium aphanidermatum, $P$. irregulare, and $P$. myriotylum in composts at different temperatures. Plant Dis. 83:356-360.

6. Blackwell, Elsie M., and Waterhouse, Grace M. 1931. Spores and spore germination in the genus Phytophthora. Trans. Br. Mycol. Soc. 15:294-310.

7. Bonanomi, G., Antignani, V., Capodilupo, M., and Scala, F. 2010. Identifying the characteristics of organic soil amendments that suppress soilborne plant diseases. Soil Biol. Biochem. 42:136-144.

8. Chen, M.-H., and Nelson, E. B. 2008. Seed-colonizing microbes from municipal biosolids compost suppress Pythium ultimum damping-off on different plant species. Phytopathology 98:1012-1018.

9. Chen, M.-H., Jack, A. L. H., McGuire, I. C., and Nelson, E. B. 2012. Seedcolonizing bacterial communities associated with the suppression of Pythium seedling disease in a municipal biosolids compost. Phytopathology 102:478-489.

10. Chen, M.-H., and Nelson, E. B. 2012. Microbial-induced carbon competition in the spermosphere leads to pathogen and disease suppression in a municipal biosolids compost. Phytopathology 102:588-596.

11. Clerk, G. C. 1972. Germination of sporangia of Phytophthora palmivora (Butl) Butl. Ann. Bot. 36:801-807.

12. Deacon, J. W., and Donaldson, S. P. 1993. Molecular recognition in the homing responses of zoosporic fungi, with special reference to Pythium and Phytophthora. Mycol. Res. 97:1153-1171.

13. de Souza, J. T., de Boer, M., de Waard, P., van Beek, T. A., and Raaijmakers, J. M. 2003. Biochemical, genetic, and zoosporicidal properties of cyclic lipopeptide surfactants produced by Pseudomonas fluorescens. Appl. Environ. Microbiol. 69:7161-7172.

14. Duniway, J. M. 1979. Water relations of water molds. Annu. Rev. Phytopathol. 17:431-460.

15. Farr, D. F., and Rossman, A. Y. 2012. Fungal Databases, Systematic Mycol- ogy and Microbiology Laboratory, ARS, USDA. http://nt.ars-grin.gov/ fungaldatabases/

16. Folman, L. B., Postma, J., and Van Veen, J. A. 2003. Inability to find consistent bacterial biocontrol agents of Pythium aphanidermatum in cucumber using screens based on ecophysiological traits. Microb. Ecol. 45:72-87.

17. Hadar, Y., and Papadopoulou, K. K. 2012. Suppressive composts: microbial ecology links between abiotic environments and healthy plants. Annu. Rev. Phytopathol. 50:133-153.

18. Hardham, A. R., and Hyde, G. J. 1997. Asexual sporulation in the oomycetes. In: Advances in Botanical Research Incorporating Advances in Plant Pathology, Vol. 24. J. H. T. I. C. Andrews, ed. Elsevier Academic Press, Inc., San Diego, CA.

19. Hardy, G. E. S., and Sivasithamparam, K. 1991. Sporangial responses do not reflect microbial suppression of Phytophthora drechsleri in composted eukalyptus bark mix. Soil Biol. Biochem. 23:757-765.

20. Heintz, C. E. 1970. Zoosporogenesis in Pythium middletonii. Am. J. Bot. 57:760.

21. Hemmes, D. E., and Hohl, H. R. 1969. Ultrastructural changes in directly germinating sporangia of Phytophthora parasitica. Am. J. Bot. 56:300-313.

22. Heungens, K., and Parke, J. L. 2000. Zoospore homing and infection events: effects of the biocontrol bacterium Burkholderia cepacia AMMDR1 on two oomycete pathogens of pea (Pisum sativum L.). Appl. Environ. Microbiol. 66:5192-5200.

23. Heungens, K., and Parke, J. L. 2001. Postinfection biological control of oomycete pathogens of pea by Burkholderia cepacia AMMDR1. Phytopathology 91:383-391.

24. Islam, M. T., and von Tiedemann, A. 2011. 2,4-Diacetylphloroglucinol suppresses zoosporogenesis and impairs motility of Peronosporomycete zoospores. World J. Microbiol. Biotechnol. 27:2071-2079.

25. Kruijt, M., Tran, H., and Raaijmakers, J. M. 2009. Functional, genetic and chemical characterization of biosurfactants produced by plant growthpromoting Pseudomonas putida 267. J. Appl. Microbiol. 107:546-556.

26. Lunney, C. Z., and Bland, C. E. 1976. Ultrastructural study of zoosporogenesis in Pythium proliferum deBary. Protoplasma 88:85-100.

27. Michel, B. E. 1983. Evaluation of the water potentials of solutions of polyethylene glycol 8000 both in the absence and presence of other solutes. Plant Physiol. 72:66-70.

28. Nelson, E. B. 2004. Microbial dynamics and interactions in the spermosphere. Annu. Rev. Phytopathol. 42:271-309.

29. Nelson, E. B. 2006. Rhizosphere regulation of preinfection behavior of oomycete plant pathogens. In: Microbial Activity in the Rhizosphere. K. G. Mukerji, C. Manoharachary, and J. Singh, eds. Springer-Verlag, Berlin.

30. Nelson, E. B., and Craft, C. M. 1989. Comparative germination of cultureproduced and plant-produced sporangia of Pythium ultimum in response to soluble seed exudates and exudate components. Phytopathology 79:1009-1013.

31. Neto, V. B. D., and Otoni, W. C. 2003. Carbon sources and their osmotic potential in plant tissue culture: does it matter? Sci. Hortic. 97:193-202.

32. Pereira, D. I. B., Santurio, J. M., Alves, S. H., Argenta, J. S., Cavalheiro, A. S., and Ferreiro, L. 2008. In vitro zoosporogenesis among oomycetes Pythium insidiosum isolates. Cienc. Rural 38:143-147.

33. Raaijmakers, J. M., and Mazzola, M. 2012. Diversity and natural function of antibiotics produced by beneficial and plant pathogenic bacteria. Annu. Rev. Phytopathol. 50:403-424.

34. Ruben, D. M., Frank, Z. R., and Chet, I. 1980. Factors affecting behavior and developmental synchrony of germinating oospores of Pythium apha nidermatum. Phytopathology 70:54-59.

35. Ruben, D. M., Frank, Z. R., Chet, I., and Sklan, D. 1981. Changes in the chemical composition of oospores of Pythium aphanidermatum during bimodal germination. Can. J. Microbiol. 27:536-543.

36. Shang, H. Z., Chen, J. J., Handelsman, J., and Goodman, R. M. 1999. Behavior of Pythium torulosum zoospores during their interaction with tobacco roots and Bacillus cereus. Curr. Microbiol. 38:199-204.

37. Shipton, W. A. 1982. Physiology of growth and asexual reproduction of a Pythium causing equine phycomycosis. Trans. Br. Mycol. Soc. 79:221-227.

38. Shipton, W. A. 1985. Zoospore induction and release in a Pythium causing equine phycomycosis. Trans. Br. Mycol. Soc. 84:147-155.

39. Shipton, W. A. 1987. Regulation by ions of zoospore release in Pythium. Aust. J. Bot. 35:79-89.

40. Stanghellini, M. E., and Burr, T. J. 1973. Germination in vivo of Pythium aphanidermatum in oospores and sporangia. Phytopathology 63:1493-1496.

41. Taylor, C. F., Smoot, J. J., Quinn, D. O., Rohde, R. A., and Elliott, E. S. 1955. Effect of brief exposures at $40^{\circ} \mathrm{C}$ of sporangia of Phytophthora infestans. Phytopathology 45:673-675.

42. Termorshuizen, A. J., van Rijn, E., van der Gaag, D. J., Alabouvette, C., Chen, Y., Lagerlof, J., Malandrakis, A. A., Paplomatas, E. J., Ramert, B., Ryckeboer, J., Steinberg, C., and Zmora-Nahum, S. 2006. Suppressiveness of 18 composts against 7 pathosystems: variability in pathogen response. Soil Biol. Biochem. 38:2461-2477.

43. van West, P., Morris, B. M., Reid, B., Appiah, A. A., Osborne, M. C., Campbell, T. A., Shepherd, S. J., and Gow, N. A. R. 2002. Oomycete plant pathogens use electric fields to target roots. Mol. Plant-Microbe Interact. 15:790-798.

44. Webster, J., and Dennis, C. 1967. The mechanism of sporangial discharge in Pythium middletonii. New Phytol. 66:307-313. 